\title{
Physical Exercise and Immune System: Perspectives on the COVID-19 pandemic
}

\author{
Alex Cleber Improta-Caria1,2* (1), Úrsula Paula Renó Soci ${ }^{3}$ (1) , Cristiano Silva Pinho ${ }^{1,4}$ (1), \\ Roque Aras Júnior ${ }^{1}\left(\mathbb{D}\right.$, Ricardo Augusto Leoni De Sousa ${ }^{5}$ (1) , Theolis Costa Barbosa Bessa ${ }^{6}$
}

\begin{abstract}
Physical exercise training (PET) has been considered an excellent non-pharmacological strategy to prevent and treat several diseases. There are various benefits offered by PET, especially on the immune system, promoting changes in the morphology and function of cells, inducing changes in the expression pattern of pro and anti-inflammatory cytokines. However, these changes depend on the type, volume and intensity of PET and whether it is being evaluated acutely or chronically. In this context, PET can be a tool to improve the immune system and fight various infections. However, the current COVID-19 pandemic, caused by SARS-CoV-2, which produces cytokine storm, inducing inflammation in several organs, with high infection rates in both sedentary and physically active individuals, the role of PET on immune cells has not yet been elucidated. Thus, this review focused on the role of PET on immune system cells and the possible effects of PET-induced adaptive responses on SARS-CoV-2 infection and COVID-19.

KEYWORDS: Exercise. Immune system. Coronavirus infections. Pandemics.
\end{abstract}

\section{INTRODUCTION}

The beneficial effects of physical exercise training (PET) for individuals with type 2 diabetes and obesity ${ }^{1}$, inflammatory illneses ${ }^{2}$, arterial hypertension ${ }^{3}$, heart failure ${ }^{4}$, Alzheimer's disease $^{5}$, among other diseases, are well established. Improved immune function is demonstrated with all types of PET, such as walking, running, swimming, and cycle ergometer. The beneficial effects on the immune system include cell regulation and modulation of gene expression and signaling pathways associated with the inflammatory process ${ }^{6}$.

The effects of PET on the immunomodulatory response are related to the type of stimulus applied, taking into account exercise duration, intensity and frequency, both in physiological and pathological situations ${ }^{7,8}$. Notably, the acute response (during or shortly after exercise) of high-intensity exercise results in transient suppression of the immune system, making individuals more susceptible to infections by viruses and bacteria ${ }^{9}$, as well as viral reactivation, whereas continued training (long training period) generates a chronic adaptation of this organism, increasing the defense of the immune system against microorganisms and pathogens ${ }^{10}$.

The ongoing COVID-19, caused by the novel coronavirus (SARS-CoV-2) rose questions about the appropriateness of PET during quarantine time, given the fact

\footnotetext{
1Universidade Federal da Bahia, Faculdade de Medicina, Programa de Pós-Graduação em Medicina e Saúde - Salvador (BA), Brazil.

${ }^{2}$ Sociedade Brasileira de Cardiologia, Departamento de Educação Física em Cardiologia - Salvador (BA), Brazil.

3Universidade de São Paulo, Escola de Educação Física e Esporte, Laboratório de Bioquímica e Biologia Molecular do Exercício - São Paulo (SP), Brazil.

${ }^{4}$ União de Faculdades de Alagoas e Faculdade Figueiredo Costa - Maceió (AL), Brazil.

${ }^{5}$ Universidade Federal dos Vales do Jequitinhonha e Mucuri, Programa Multicêntrico de Pós-Graduação em Ciências Fisiológicas - Diamantina (MG), Brazil.

${ }^{6}$ Fundação Oswaldo Cruz, Instituto Gonçalo Moniz - Salvador (BA), Brazil.

*Corresponding author: alexcaria.personal@hotmail.com

Conflicts of interest: the authors declare there are no conflicts of interest. Funding: Coordination for the Improvement of Higher Education Personnel (Coordenação de Aperfeiçoamento de Pessoal de Nível Superior - Brazil - CAPES), that partly financed the present study - Finance Code 001.

Received on September 22, 2020. Accepted on October 21, 2020.
} 
that infection also affects the immune system ${ }^{11}$. Seen that, PET being used as a non-pharmacological tool during the COVID-19 pandemic is thus questionable. We aimed to briefly debate in two topics the enigmatic role of PET in favoring or not a positive adaptation of the immune system to prevent COVID-19: 1 - how PET acutely and chronically induces adaptation of the innate immune system cells in response to aerobic and resistance training, and 2 - the possible effects of PET-induced adaptive responses on SARS-CoV-2 infection.

\section{INNATE AND ADAPTIVE IMMUNOLOGIC RESPONSE}

The immune response is highly dynamic and involves cell components that can be simplistically described as belonging to the Innate (II) and Adaptive Immune System (AI). The Natural Killers, Macrophages, Eosinophils, Neutrophils, and Dendritic Cells are the II cells, and they act on the primary defense against infectious agents, by quickly recognizing atypical molecules of pathogens, toxic products or damaged tissue, and triggering the "danger" signal, that directs AI cells to a specific response against the invader ${ }^{12-15}$. The II cells are formed in the germ line; they do not divide, do not form clones, and do not produce memory cells. In contrast, AI cells bear specific antigen receptors ( $T$ lymphocytes and B lymphocytes), they are formed in the somatic lineage and may undergo hypermutations, thereby increasing their affinity to the antigen. $B$ and $T$ cells possess genetically rearranged and highly diverse antigen receptors, imparting specificity in recognition to these cells.

In contrast with the II response, the AI response becomes more efficient with each successive encounter with the same pathogen, a phenomenon called immune memory ${ }^{16,17}$. AI response is induced by successive memory formation by $\mathrm{B}$ an $\mathrm{T}$ cells and is influenced by the II response. PET induces changes in these lymphocytes because of the high shear stress on artery walls, of the stimulation of the sympathetic nervous system and of the increased adrenaline secretion. It induces lymphocytosis of both $\mathrm{B}$ and $\mathrm{T}$ lymphocytes ${ }^{18,19}$, and these changes are proportional to PET duration and intensity ${ }^{20}$. However, negative effects on AI function were also reported, such as $\mathrm{T}$ lymphocyte apoptosis after physical testing to exhaustion (Figure 1$)^{21}$.

As SARS-CoV-2 is a new virus, human immunity is being developed during the pandemic outbreak in the general population. Thus, this review's focus is mainly on PET-induced chronic and acute adaptation in the II cells, as described in the topics below.

\section{PHYSICAL EXERCISE AND NEUTROPHILS}

PET induces changes in the phagocytic activity of neutrophils. This activity may be reduced as an acute response to different high-intensity exercise modalities ${ }^{22}$ or increased after moderate-intensity training as a chronic adaptation ${ }^{23}$. However, this response is still controversial, since there are different protocols for the same PET modality, besides the inherent peculiarities of the studied populations. PET induces the production of reactive oxygen species (ROS) through the acute response or chronic adaptation of the immune system, according to its modality and protocol ${ }^{24}$. For example, increased ROS production mediated by neutrophils and apoptosis were related to PET $^{25}$; however, other studies have shown an opposite effect, with reduced ROS production by neutrophils after moderate intensity $\mathrm{PET}^{24,26}$. Still regarding the impact of PET on neutrophils, several studies have shown reduction of chemotaxis after high-intensity aerobic exercise ${ }^{9,27}$.

\section{PHYSICAL EXERCISE AND MACROPHAGES}

Acute and chronic adaptation of macrophage functions were shown as a result of PET. Unlike neutrophils, studies unanimously report increased phagocytic activity of macrophages after PET, regardless if moderate or of high intensity until exhaustion ${ }^{6,28}$. Other PET-modulated biological processes in macrophages include augmented ROS production after intense exercise to exhaustion; improved antitumor activity upon moderate and high intensity exercise, due to increased cytotoxic activity against neoplastic cells ${ }^{29}$, higher nitric oxide production after moderate-intensity $\mathrm{PET}^{6}$, reduced expression of class II antigen presenting molecules in high and moderate-intensity PET and increased macrophage chemotaxis after intense PET until exhaustion ${ }^{30}$. As observed in neutrophils, there are controversies regarding the beneficial effects of exercise on macrophage function due to the variety of types, modality, and protocols of PET, as well as the diversity of biological process evaluated.

\section{PHYSICAL EXERCISE AND NATURAL KILLER CELLS}

High-intensity PET reduced the cytotoxic activity of Natural Killer (NK) cells ${ }^{31}$. Increased NK cell apoptosis has also been reported after treadmill running ${ }^{32}$ and after a marathon competition ${ }^{33}$. However, other studies have shown that both acute exercise and chronic PET increase NK cell number ${ }^{34}$, NK cytotoxicity, and the production of cytokines, such as IFN- $\gamma$, 


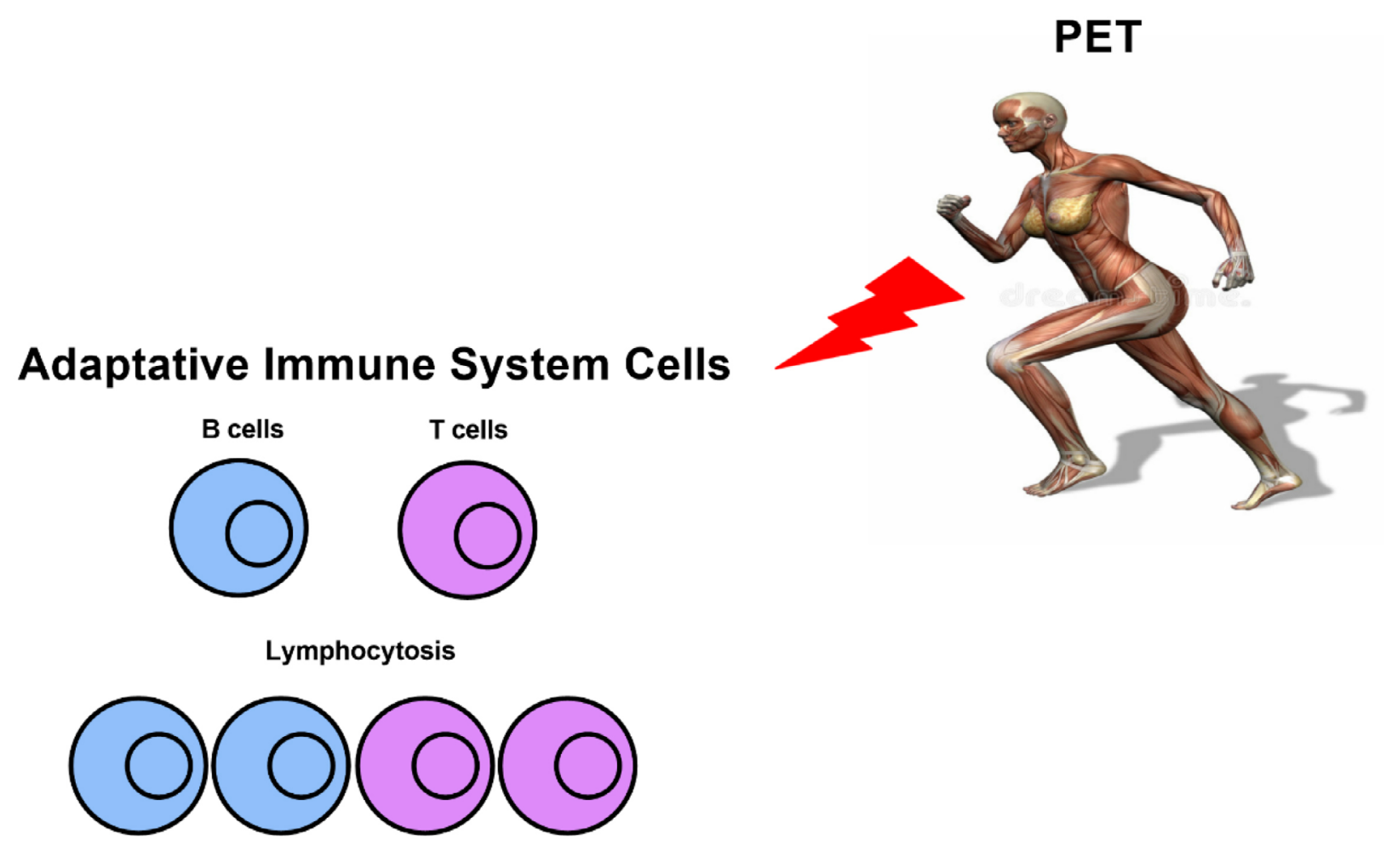

Physical testing to exhaustion leads to T lymphocyte apoptosis

Figure 1. Impact of physical exercise training (PET) on cells of the adaptative immune system

TGF- $\beta$, and interleukin 10 (IL-10), after both moderate and high-intensity exercise ${ }^{35,36}$. The responses obtained may vary due to the different protocols analyzed, as well as different types of PET used (Figure 2).

\section{PHYSICAL EXERCISE AND EXTRACELLULAR SUPEROXIDE DISMUTASE (ECSOD) ENZYMES}

Moderate-intensity PET increased the expression of EcSOD enzymes and reduced ROS production, attenuating cytotoxic activity of immune cells ${ }^{37,38}$. Furthermore, EcSOD, a molecular transducer of health benefits of exercise, has been associated with lower endothelial tissues damages ${ }^{39}$.

\section{PHYSICAL EXERCISE,} IMMUNE SYSTEM AND COVID-19: WHAT IS THE EVIDENCE?

There is no available data about the effects of PET on the immune response against coronaviruses. The only original study considering possible effects of PET in the context of the COVID-19 pandemic focused on the need to consider the health condition of people who were not infected by SARS-CoV-2, especially regarding individuals that ceased labor activities due to restrictive measures enforced during the outbreak. This condition may predispose subjects to the development of mood disorders, such as depression ${ }^{36}$, and possibly modulate the responses of their immune system. Since there is no consistent biological basis of a beneficial biological effect of exercise during the COVID-19 pandemic, the main focus to prescribe a PET program at this time should be light- to moderate-intensity aerobic exercises, recreation, wellness and resilience-related to a new routine, and not to the development of sports performance (Figure 3).

\section{FINAL CONSIDERATIONS}

PET produces controversial effects on the immune system, depending on the protocols adopted. Although many beneficial effects of PET were demonstrated in the prevention or treatment of a wide range of diseases, whether prescribing 


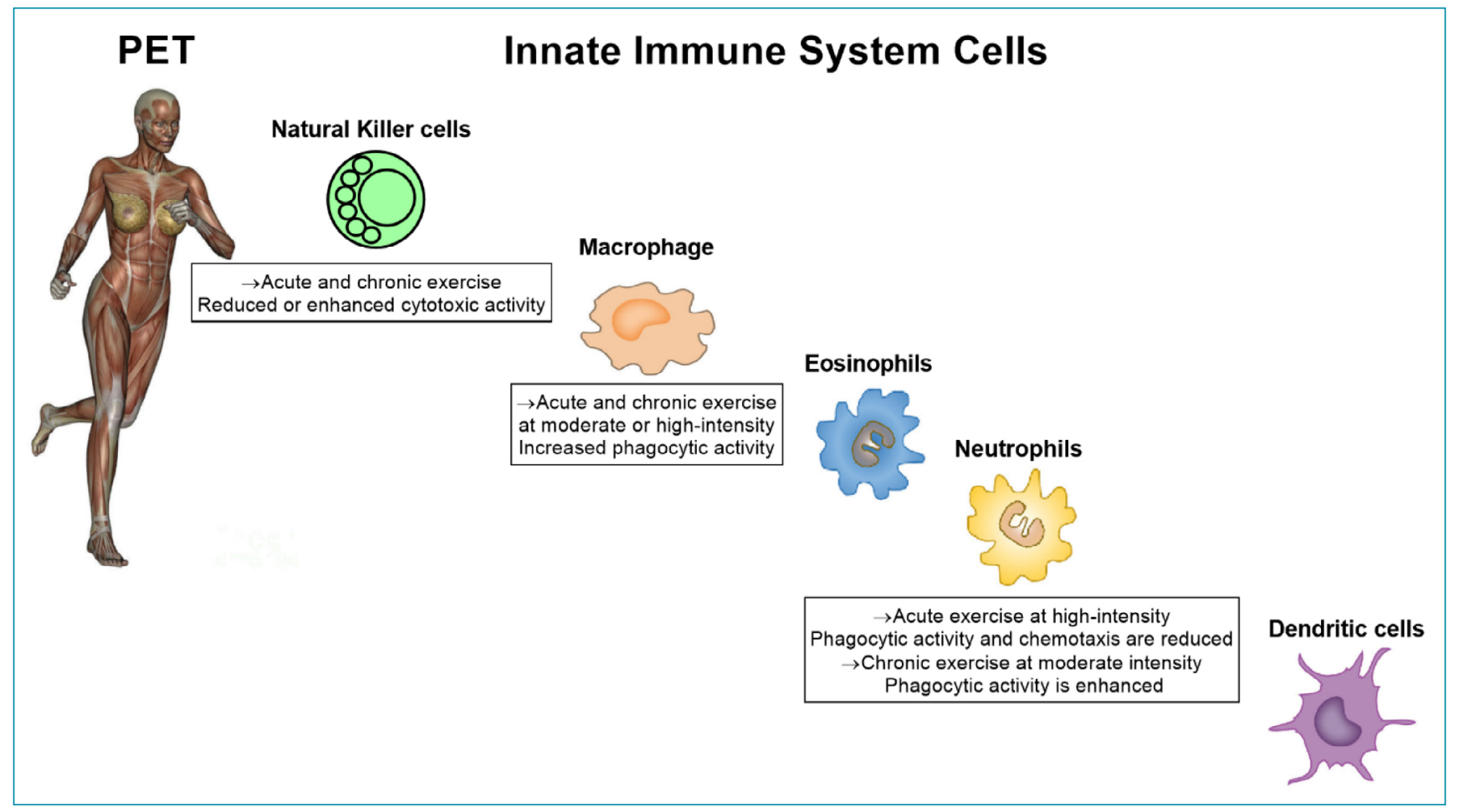

Figure 2. Effects of physical exercise training (PET) on innate immune system cells.

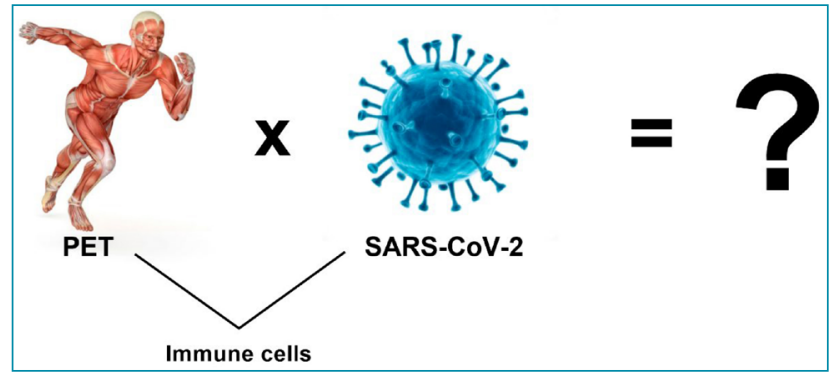

Figure 3. Elucidation of the mechanisms of physical exercise training (PET) on immune system cells in individuals with COVID-19: the great challenge

PET during COVID-19 leads to improved defense against the virus, when employed as a prophylactic measure, or induces changes in immune system, which would increase susceptibility to virus infection, or stimulate inflammatory processes and virus-induced damage, in the context of treatment, remains unknown. Considering that high-intensity PET sessions might result in transient immune depression and predispose individuals to viral infections as well as viral reactivation, we suggest that exercise prescription during quarantine should be done with caution. We advise for intensified monitoring rather than what is usually performed in gymnasiums, focusing mainly on the control of exercise intensity, duration, and frequency.

Further caution should be taken for PET practice given the fact that some individuals infected with SARS-CoV-2 CAN BE asymptomatic, but may still develop symptoms as a result of PET-driven transient immune depression, which can be more harmful than beneficial for these individuals. On the other hand, uninfected individuals who perform PET may undergo adaptation of their immune defense system that may improve innate immune cell functionality, leading to a reinforced adaptive sensibilization and production of antibodies, compared to uninfected individuals who are not training, which can help in infection prophylaxis and symptoms attenuation in case of infection.

\section{ACKNOWLEDGMENTS}

We would like to thank the Coordination for the Improvement of Higher Education Personnel (Coordenação de Aperfeiçoamento de Pessoal de Nível Superior - Brazil CAPES), that partly financed the present study - Finance Code 001. We would also like to thank the Graduate Program in Medicine and Health, Faculty of Medicine, Universidade Federal da Bahia. 


\section{AUTHORS “CONTRIBUTION}

ACIC: Conceptualization; Data Curation; Formal Analysis; Investigation; Supervision; Writing - Original Draft; Writing - Review \& Editing. UPRS: Data Curation; Formal Analysis;
Investigation; Writing - Original Draft. CSP: Investigation; Writing - Original Draft. RAJ: Supervision. RALS: Investigation; Writing - Original Draft; Validation. TCBB: Formal Analysis; Supervision; Validation.

\section{REFERENCES}

1. Improta Caria AC, Nonaka CKV, Pereira CS, Soares MBP, Macambira SG, Souza BSF. Exercise training-induced changes in MicroRNAs: beneficial regulatory effects in hypertension, type 2 diabetes, and obesity. Int J Mol Sci. 2018;19(11):3608. https://doi.org/10.3390/ijms19113608

2. Bilski J, Brzozowski B, Mazur-Bialy A, Sliwowski Z, Brzozowski $\mathrm{T}$. The role of physical exercise in inflammatory bowel disease. Biomed Res Int. 2014;2014:429031. https://doi. org/10.1155/2014/429031

3. Liu X, Zhang D, Liu Y, Sun X, Han C, Wang B, et al. Doseresponse association between physical activity and incident hypertension: a systematic review and meta-analysis of cohort studies. Hypertension. 2017;69(5):813-20. https:// doi.org/10.1161/HYPERTENSIONAHA.116.08994

4. Prado DML, Rocco EA. The benefits of exercise training on aerobic capacity in patients with heart failure and preserved ejection fraction. Adv Exp Med Biol. 2017; 1000:51-64. https:// doi.org/10.1007/978-981-10-4304-8_4

5. Improta-Caria AC, Nonaka CKV, Cavalcante BRR, Sousa RAL, Aras Júnior R, Souza BSF. Modulation of microRNAs as a potential molecular mechanism involved in the beneficial actions of physical exercise in Alzheimer disease. Int J Mol Sci. 2020;21(14):4977. https://doi.org/10.3390/ijms21144977

6. Silveira EM, Rodrigues MF, Krause MS, Vianna DR, Almeida BS, Rossato JS, et al. Acute exercise stimulates macrophage function: possible role of NF-kappaB pathways. Cell Biochem Funct. 2007;25(1):63-73. https://doi.org/10.1002/cbf.1365

7. Allen J, Sun Y, Woods JA. Exercise and the regulation of inflammatory responses. Prog Mol Biol Transl Sci. 2015;135:33754. https://doi.org/10.1016/bs.pmbts.2015.07.003

8. Elia J, Kane S. Adult inflammatory bowel disease, physical rehabilitation, and structured exercise. Inflamm Bowel Dis. 2018;24(12):2543-9. https://doi.org/10.1093/ibd/izy199

9. Wolach B, Gavrieli R, Ben-Dror SG, Zigel L, Eliakim A, Falk B. Transient decrease of neutrophil chemotaxis following aerobic exercise. Med Sci Sports Exerc. 2005;37(6):949-54. PMID: 15947719

10. Nieman DC. Exercise, infection, and immunity: practical applications. In: Committee on Military Nutrition Research, Institute of Medicine. Military strategies for sustainment of nutrition and immune function in the field. Washington: National Academies Press (US); 1999. [cited on Sept 5, 2020]. Available from: https://www.ncbi.nlm.nih.gov/books/ NBK230961/

11. Mauro G, Scavone C, Rafaniello C, Rossi F, Capuano A. SARS-Cov-2 infection: Response of human immune system and possible implications for the rapid test and treatment. Int Immunopharmacol. 2020;84:106519. https://doi.org/10.1016/j. intimp.2020.106519
12. Akira S, Uematsu S, Takeuchi O. Pathogen recognition and innate immunity. Cell. 2006;124(4):783-801. https://doi. org/10.1016/j.cell.2006.02.015

13. Kumar H, Kawai T, Akira S. Pathogen recognition by the innate immune system. Int Rev Immunol. 2011;30(1):16-34. https:// doi.org/10.3109/08830185.2010.529976

14. Iwasaki A, Medzhitov R. Control of adaptive immunity by the innate immune system. Nat Immunol. 2015;16(4):343-53. https://doi.org/10.1038/ni.3123

15. Vivier E, Raulet DH, Moretta A, Caligiuri MA, Zitvogel L, Lanier LL, et al. Innate or adaptive immunity? The example of natural killer cells. Science. 2011;331(6013):44-9. https:// doi.org/10.1126/science. 1198687

16. Iwasaki A, Medzhitov R. Regulation of adaptive immunity by the innate immune system. Science. 2010;327(5963):291-5. https://doi.org/10.1126/science.1183021

17. Bonilla FA, Oettgen HC. Adaptive immunity. J Allergy Clin Immunol. 2010;125 (Suppl 2):S33-40. https://doi.org/10.1016/j. jaci.2009.09.017

18. Shepard RJ. Adhesion molecules, catecholamines and leucocyte redistribution during and following exercise. Sports Med. 2003;33(4):261-84. https://doi.org/10.2165/00007256200333040-00002

19. Campbell JP, Riddell NE, Burns VE, Turner M, van Zanten JJ, Drayson MT, et al. Acute exercise mobilises CD8+ Tlymphocytes exhibiting an effector-memory phenotype. Brain Behav Immun. 2009;23(6):767-75. https://doi.org/10.1016/j.bbi.2009.02.011

20. Shek PN, Sabiston BH, Buguet A, Radomski MW. Strenuous exercise and immunological changes: a multiple-time-point analysis of leukocyte subsets, CD4/CD8 ratio, immunoglobulin production and NK cell response. Int J Sports Med. 1995;16(7):466-74. https://doi.org/10.1055/s-2007-973039

21. Terra R, Silva SAG, Pinto VS, Dutra PML. Effect of exercise on the immune system: response, adaptation and cell signaling. Rev Bras Med Esporte. 2012;18(3):208-14. https://doi. org/10.1590/S1517-86922012000300015

22. Chinda D, Nakaji S, Umeda T, Shimoyama T, Kurakake S, Okamura $\mathrm{N}$, et al. A competitive marathon race decreases neutrophil functions in athletes. Luminescence. 2003;18(6):324-9. https:// doi.org/10.1002/bio.744

23. Hack V, Strobel G, Rau JP, Weicker $H$. The effect of maximal exercise on the activity of neutrophil granulocytes in highly trained athletes in a moderate training period. Eur J Appl Physiol Occup Physiol. 1992;65(6):520-4. https://doi.org/10.1007/ BF00602358

24. Pyne DB, Smith JA, Baker MS, Telford RD, Weidemann MJ. Neutrophil oxidative activity is differentially affected by exercise intensity and type. J Sci Med Sport. 2000;3(1):44-54. https:// doi.org/10.1016/s1440-2440(00)80047-x 
25. Levada-Pires AC, Cury-Boaventura MF, Gorjão R, Hirabara $S M$, Puggina EF, Peres CM, et al. Neutrophil death induced by a triathlon competition in elite athletes. Med Sci Sports Exerc. 2008;40(8):1447-54. https://doi.org/10.1249/ MSS.0b013e31816dc89e

26. Robson PJ, Blannin AK, Walsh NP, Castell LM, Gleeson M. Effects of exercise intensity, duration and recovery on in vitro neutrophil function in male athletes. Int J Sports Med. 1999;20(2):128-35. https://doi.org/10.1055/s-2007-971106

27. Wolach B, Falk B, Gavrieli R, Kodesh E, Eliakim A. Neutrophil function response to aerobic and anaerobic exercise in female judoka and untrained subjects. Br J Sports Med. 2000;34(1):23-8. https://doi.org/10.1136/bjsm.34.1.23

28. Su SH, Chen HI, Jen CJ. Severe exercise enhances phagocytosis by murine bronchoalveolar macrophages. J Leukoc Biol. 2001;69(1):75-80. PMID: 11200071

29. Davis JM, Kohut ML, Jackson DA, Colbert LH, Mayer EP, Ghaffar A. Exercise effects on lung tumor metastases and in vitro alveolar macrophage antitumor cytotoxicity. Am J Physiol. 1998;274(5):R1454-9. https://doi.org/10.1152/ ajpregu.1998.274.5.R1454

30. Woods JA, Ceddia MA, Kozak C, Wolters BW. Effects of exercise on the macrophage $\mathrm{MHC}$ II response to inflammation. Int J Sports Med. 1997;18(6):483-8. https://doi.org/10.1055/s-2007-972668

31. Rohde T, MacLean DA, Hartkopp A, Pedersen BK. The immune system and serum glutamine during a triathlon. Eur J Appl Physiol Occup Physiol. 1996;74(5):428-34. https://doi. org/10.1007/BF02337723

32. Mooren FC, Blöming $D$, Lechtermann A, Lerch MM, Völker K. Lymphocyte apoptosis after exhaustive and moderate exercise. J Appl Physiol (1985). 2002;93(1):147-53. https:// doi.org/10.1152/japplphysiol.01262.2001
33. Mooren FC, Lechtermann A, Völker K. Exercise-induced apoptosis of lymphocytes depends on training status. Med Sci Sports Exerc. 2004;36(9):1476-83. https://doi.org/10.1249/01. mss.0000139897.34521.e9

34. Moro-García MA, Fernández-García B, Echeverría A, RodríguezAlonso M, Suárez-García FM, Solano-Jaurrieta JJ, et al. Frequent participation in high volume exercise throughout life is associated with a more differentiated adaptive immune response. Brain Behav Immun. 2014;39:61-74. https://doi. org/10.1016/j.bbi.2013.12.014

35. Millard AL, Valli PV, Stussi G, Mueller NJ, Yung GP, Seebach JD. Brief exercise increases peripheral blood NK cell counts without immediate functional changes, but impairs their responses to ex vivo stimulation. Front Immunol. 2013;4:125. https://doi.org/10.3389/fimmu.2013.00125

36. Zhang SX, Wang Y, Rauch A, Wei F. Unprecedented disruption of lives and work: Health, distress and life satisfaction of working adults in China one month into the COVID-19 outbreak. Psychiatry Res. 2020;288:112958. https://doi.org/10.1016/j. psychres.2020.112958

37. Pinho CS. COVID-19: isolamento social e imunomodulação através do exercício físico. Salvador: CBL - Câmara Brasileira do Livro; 2020

38. Yan Z, Spaulding HR. Extracellular superoxide dismutase, a molecular transducer of health benefits of exercise. Redox Biol. 2020;32:101508. https://doi.org/10.1016/j.redox.2020.101508

39. Call JA, Donet J, Martin KS, Sharma AK, Chen X, Zhang $J$, et al. Muscle-derived extracellular superoxide dismutase inhibits endothelial activation and protects against multiple organ dysfunction syndrome in mice. Free Radic Biol Med. 2017;113:212-23. https://doi.org/10.1016/j. freeradbiomed.2017.09.029 